\title{
AWARENESS, STRESS, ANXIETY, AND DEPRESSION AMONG HYPERTENSIVE PATIENTS ATTENDING CARDIAC OUTPATIENT DEPARTMENT IN A SUPER SPECIALTY HOSPITAL
}

\author{
SUSHIL KUMAR SHARMA ${ }^{1}$, VINEETA SAWHNEY'* \\ ${ }^{1}$ Department of Cardiology, Super Speciality Hospital, Government Medical College, Jammu, Jammu and Kashmir, India. ${ }^{2}$ Department of \\ Pharmacology, Government Medical College, Srinagar, Jammu and Kashmir, India. Email: vineetasawhney@gmail.com
}

Received: 15 March 2016, Revised and Accepted: 24 March 2016

\section{ABSTRACT}

Objective: Hypertension is a major risk factor for cardiovascular disease and its association with negative emotions may increase their risk for the development of mental health disorders. The main objective of the study was to assess the awareness, stress, anxiety, and depression among hypertensive patients attending cardiac outpatient department (OPD).

Methods: This study was conducted in cardiac OPD of Super Speciality Hospital associated with Government Medical College, Jammu, for a period of 1-month commencing from $1^{\text {st }}$ October to $31^{\text {st }}$ October 2015. Hypertensive patients were given a questionnaire regarding socio-demographic profile, risk factors, and awareness for high blood pressure, and prevalence of stress, anxiety, and depression was assessed using a structured validated questionnaire DASS-21 [depression, anxiety, and stress scale-21]

Results: It was observed that most (72.5\%) of the patients were aware of symptoms and its complications and regarding psychological symptoms mild to severe depressive symptoms were present in $10 \%$, anxiety in $70 \%$, and stress in $10 \%$ of patients.

Conclusion: There is need of psychiatric evaluation and counseling in these patients and support services to be made available to these patients.

Keywords: Hypertension, Awareness, Stress, Anxiety, Depression, Depression; anxiety and stress scale-21.

(C) 2016 The Authors. Published by Innovare Academic Sciences Pvt Ltd. This is an open access article under the CC BY license (http://creativecommons. org/licenses/by/4. 0/) DOI: http://dx.doi.org/10.22159/ajpcr.2016.v9i5.11711

\section{INTRODUCTION}

Hypertension is a global challenge with high morbidity and mortality rates. The etiology of hypertension is multifactorial, which results from the combined influence of genetic and environmental factors. It predisposes to coronary heart disease and cardiac dysfunction and has deleterious neurological effects on retina, central nervous system, and kidneys. The overall prevalence of raised blood pressure (BP) in adults aged 25 years and over was around $40 \%$ in 2008 [1]. However, because of population growth and aging, the number of people with hypertension rises from 600 million in 1980 to 1 billion in 2008 [1]. It was seen that awareness of hypertension among those affected by the disease is generally high as compared to the general population [2]. The WHO celebrates $17^{\text {th }}$ May as "World Hypertension Day" and the main aim of this day is to provide awareness of hypertension so that we can prevent the complications arising out of high BP such as heart attack, heart failure, stroke, kidney failure, retinal hemorrhage, and atherosclerosis. Besides, it is one of the modifiable risk factors as hypertensive patients also experience many profound emotions which increase their risk for the development of mental health disorders, particularly anxiety and depression $[3,4]$.

Depression is a burdensome disease of global importance [5], and although prevalent, it is mostly undiagnosed in patients with hypertension [6]. The research evidence suggests that anxiety is another significant cause of increased BP and is an independent predictor of future hypertension [7]. Similarly, stress is known to be significantly correlated with hypertension and causes many cardiac problems [8]. Natural reaction of the cardiovascular response to stress is the increase in heart rate. Keeping all these factors in mind, the present study was carried out to evaluate the awareness and psychological aspects in hypertensive patients which has been overlooked by physicians, and in our setup, it is the first study of its kind.

\section{METHODS}

This cross-sectional study was conducted in the Outpatient Department of Cardiology in Super Speciality Hospital of Government Medical College, Jammu, for a period of 1-month commencing from $1^{\text {st }}$ October to $31^{\text {st }}$ October 2015. 200 hypertensive patients attending cardiac outpatient department were recruited in the study. Eligibility to participate in the study was that the patient should be diagnosed case of hypertension or hypertension with other comorbid conditions and should be on antihypertensive medication for a minimum period of 2-months. These patients then were interviewed using a pre-tested, structured, mostly closed-ended questionnaire, and data were collected for 2 days in a week. The questionnaire included the socio-demographic profile, risk factors, and awareness for high BP, whereas for the prevalence of stress, anxiety, and depression, a structured validated questionnaire depression, anxiety, and stress scale-21 (DASS-21) was used [9]. The results were expressed in percentage.

\section{RESULTS}

Out of 200 studied patients, majority (60\%) were males and $61 \%$ of the studied population belonged to the age group of 41-60 years with $64 \%$ of them coming from rural areas and have to travel at least for 1-2 hrs to reach the hospital. The majority (80\%) were married and were Hindus having education up to $10^{\text {th }}$ standard and were government employees with a monthly income of Rs. 1000-10000. In the present study, majority (73\%) of patients were non-smoker and non-alcoholic (Table 1).

Regarding the patient's awareness about the disease, $72.5 \%$ of patients knew that high BP is a lifelong disease, and thus, the treatment is lifelong with only a few of them being of the opinion that treatment was only for 2-4 weeks, and majority (60.5\%) of patients were under the impression that a person can be labeled as hypertensive only when his/her BP is more than 140/90. However, majority (62.5\%) of patients were aware of the consequences of high BP like its long-term effects 
Table 1: Demographic characteristics of study sample

\begin{tabular}{|c|c|}
\hline Variables & Frequency (\%) \\
\hline \multicolumn{2}{|l|}{ Sex } \\
\hline Male & $120(60)$ \\
\hline Female & $80(40)$ \\
\hline \multicolumn{2}{|l|}{ Age } \\
\hline $18-40$ & $10(5)$ \\
\hline $41-60$ & $122(61)$ \\
\hline 60 & $68(34)$ \\
\hline \multicolumn{2}{|l|}{ Residence } \\
\hline Rural & $128(64)$ \\
\hline Urban & $72(36)$ \\
\hline \multicolumn{2}{|l|}{ Marital status } \\
\hline Single & $2(1)$ \\
\hline Married & $160(80)$ \\
\hline Divorced & $8(4)$ \\
\hline Widowed & $30(15)$ \\
\hline \multicolumn{2}{|l|}{ Religion } \\
\hline Hindu & $170(85)$ \\
\hline Muslim & $15(7.5)$ \\
\hline Other & $15(7.5)$ \\
\hline \multicolumn{2}{|l|}{ Employment } \\
\hline Government & $67(33.5)$ \\
\hline Retired & $24(12)$ \\
\hline Housewife & $53(26.5)$ \\
\hline Businessman & $17(8.5)$ \\
\hline Farmer & $31(15.5)$ \\
\hline Any other (army personal) & $8(4)$ \\
\hline \multicolumn{2}{|l|}{ Educational status } \\
\hline Degree & $46(23)$ \\
\hline Diploma & $18(9)$ \\
\hline $10^{\text {th }}$ standard & $110(55)$ \\
\hline Cannot read & $26(13)$ \\
\hline \multicolumn{2}{|l|}{ Monthly income } \\
\hline $1000-10000$ & $110(55)$ \\
\hline$>10,000$ & $70(35)$ \\
\hline$<1000$ & $20(10)$ \\
\hline \multicolumn{2}{|l|}{ Distance from hospital } \\
\hline More than 2 hrs & $47(23.5)$ \\
\hline Between 1-2 hrs & $90(45)$ \\
\hline Up to $1 \mathrm{hr}$ & $63(31.5)$ \\
\hline \multicolumn{2}{|l|}{ Habits } \\
\hline \multirow[t]{2}{*}{ Smoking } & Yes - 54 (27) \\
\hline & No - 146 (73) \\
\hline \multirow[t]{2}{*}{ Alcohol } & Yes - 54 (27) \\
\hline & No - $146(73)$ \\
\hline
\end{tabular}

on the heart, kidneys, and brain. Among the studied population, 84\% of patients would give the history of headache and palpitation and were aware of the fact the lifestyle modification in the form of regular physical exercises, weight reduction, and reducing daily salt intake has an important role in controlling high BP (Table 2).

On assessing the psychological symptoms with DASS-21 scale [9], it was seen that $90 \%$ of patients were not having any symptoms of depression and stress, whereas $30 \%$ were free from features of anxiety as well. Mild depression was seen in 11 (5.5\%), anxiety in 40 (20\%), and stress in $20(10 \%)$ of the patients. Moderate depression and anxiety were found in $9(4.5 \%)$ and $40(20 \%)$ of the patients, respectively. Out of 200 patients, $60(30 \%)$ of them had severe symptoms of anxiety (Table 3).

\section{DISCUSSION}

Hypertension is a known risk factor for cardiovascular disease, and the term hypertension itself implies a disorder initiated by tension or stress, but stress is nowhere defined, and the hypothesis is untestable [10]. However, it is an accepted fact that psychosocial factors operate through mental processes, consciously or unconsciously and cause hypertension.
Table 2: Awareness among studied patients

\begin{tabular}{|c|c|c|c|}
\hline \multirow[t]{2}{*}{$\begin{array}{l}\text { Question } \\
\text { number }\end{array}$} & \multirow[t]{2}{*}{ Awareness questions } & \multicolumn{2}{|c|}{$\begin{array}{l}\text { Response }(\%) \text {, } \\
(n=200)\end{array}$} \\
\hline & & Yes & No \\
\hline 1 & Is high BP is a lifelong disease? & 72.5 & 27.5 \\
\hline 2 & $\begin{array}{l}\text { Whether you feel different } \\
\text { with high BP? }\end{array}$ & 84 & 32 \\
\hline 3 & $\begin{array}{l}\text { Is the pressure is high when it } \\
\text { is above }>140 / 90 \text { ? }\end{array}$ & 60.5 & 39.5 \\
\hline 4 & $\begin{array}{l}\text { Can high BP cause heart, brain, } \\
\text { and kidney damage? }\end{array}$ & 62.5 & 37.5 \\
\hline 5 & Whether treatment is life long? & 72.5 & 27.5 \\
\hline 6 & $\begin{array}{l}\text { Does regular physical exercise } \\
\text { help in controlling high BP? }\end{array}$ & 79 & 21 \\
\hline 7 & $\begin{array}{l}\text { Does losing weight is helpful } \\
\text { in controlling high BP in obese } \\
\text { people? }\end{array}$ & 72.5 & 27.5 \\
\hline 8 & $\begin{array}{l}\text { Do reducing salt intake help in } \\
\text { controlling high BP? }\end{array}$ & 90 & 10 \\
\hline
\end{tabular}

BP: Blood pressure

Table 3: Distribution of degree of symptoms of depression, anxiety, and stress

\begin{tabular}{llllll}
\hline $\begin{array}{l}\text { Emotional } \\
\text { condition }\end{array}$ & n (\%) & & & & \\
\cline { 2 - 6 } & Normal & Mild & Moderate & Severe & $\begin{array}{l}\text { Extremely } \\
\text { Serve }\end{array}$ \\
\hline Depression & $180(90)$ & $11(5.5)$ & $9(4.5)$ & Nil & Nil \\
Anxiety & $60(30)$ & $40(20)$ & $40(20)$ & $60(30)$ & Nil \\
Stress & $180(90)$ & $20(10)$ & Nil & Nil & Nil \\
\hline
\end{tabular}

A high number of patients experienced mild to severe anxiety (140) followed by stress (20) and depression (20).

In countries that are in the post-transitional stage of economic and epidemiological changes, consistently higher levels of BP have been noted in lower socio-economic groups. This inverse relation has been noted with levels of education, income, and occupation. However, in societies that are transitional or pre-transitional, a higher prevalence of hypertension has been noted in upper socio-economic groups [11]. In the present study, the majority of the patients were from rural areas, married and were government employees having monthly income of Rs. 1000-10000 and had a good awareness of hypertension and more than $70 \%$ of them knew that disease and treatment is a lifelong process but only $60.5 \%$ were having knowledge about the readings of high and normal BP, which was similarly reported in other studies conducted on general population [12-14].

When psychological symptoms were assessed, we found that mild to severe depressive symptoms were present in $10 \%$, anxiety in $70 \%$, and stress in $10 \%$ of patients. So, we are on one hand trying to make patients aware of the status of their disease by asking whether they "know their number" which is the goal of WHO and International Society of Hypertension (2013-2018), but on other hand, we are finding such psychological symptoms on rise in diagnosed patients which is really worrisome. Anxiety was common among 140 (70\%) of the hypertensive patients, and this result coincides with the high prevalence of anxiety found among hypertensive patients in other countries such as South Africa, China, and Argentina in spite of cultural variability $[4,15,16]$. Anxiety in hypertension could result in a higher risk of morbidity and mortality as a result of hastened cardiovascular events [17].

Labeling the patient as hypertension by physician can itself cause increase in sympathetic activity during examination and can lead to mental stress [18] which might partly explain the associations of hypertension with worse mental health. Stress can temporarily boost $\mathrm{BP}$, for instance, some people have short-term hikes in BP when they 
visit a doctor's clinic. British researchers reported that patients with hypertension were likely to have history of panic attacks or sudden feeling of terror that strikes repeatedly [19]. In one study conducted by Spruill et al., on 214 normotensive and mildly hypertensive patients, the perception of being hypertensive was associated with greater anxiety during clinic BP measurement and a larger white coat effect [20].

Mild to moderate depressive symptoms that were seen in 20 patients showed that this information is also important because of increasing impact of depression on the global disease burden [5]. Yet, depression among hypertensive patients is usually not diagnosed [21]. As the result, such patients may be denied clinical care which takes their mental health into consideration. Use of tricyclic antidepressants was found to be associated with greater risk of hypertension [22]. However in the present study, we were not having any information regarding the use of other group of drugs. Studies have focused primarily on anxiety and depression, but significant stressful events have been reported responsible for hypertension. In the present study, 20 patients Were found to be having mild stress and maximum patients were government employees having less monthly income, and it has been seen that condition of workplace, working hours, family conditions, number of dependents are the significant social predictors of hypertension. In a Japanese study conducted by Nakanishi et al., it has been found that long working hours are responsible for hypertension [23]. In India, traditionally, the family expenditures and finances are born by the men, and in the present study, maximum patients were from rural areas where only men work and if women work they can protect their counterparts from being hypertensive.

\section{CONCLUSION}

In conclusion of the study, it was seen overall awareness in hypertensive patients is good but detecting depressive, anxiety, and stress-related symptoms in these patients are critical, and this shows that fear of suffering from disease which is lifelong and taking medication throughout life may have caused these emotional symptoms. If these hypertensive medications are combined with psychotherapy and antidepressants, it can definitely help them from severe attacks of high BP. Hence, study findings highlight the need of psychiatric evaluation, counseling, and support services which will keep their heart in good condition.

\section{REFERENCES}

1. WHO. Global Status Report of Non - Communicable Diseases 2010. Geneva: World Health Organization; 2011.

2. Familoni OB, Hypertension - How much do our patients know? Afr Health 2002;24:13.

3. DeJean D, Giacomini M, Vanstone M, Brundisini F. Patient experiences of depression and anxiety with chronic disease: A systematic review and qualitative meta-synthesis. Ont Health Technol Assess Ser 2013;13(16):1-33. eCollection 2013.

4. Vetere G, Ripaldi L, Ais E, Korob G, Kes M, Villamil A. Prevalence of anxiety disorders in patients with essential hypertension. Vertex 2007;18(71):20-5.
5. Vettath RE, Reddy YN, Reddy YN, Dutta S, Singh Z, Mathew M, et al. A multicenter cross-sectional study of mental and physical health depression in MHD patients. Indian J Nephrol 2012;22(4):251-6.

6. Scalco AZ, Scalco MZ, Azul JB, Lotufo Neto F. Hypertension and depression. Clinics (Sao Paulo) 2005;60(3):241-50.

7. Rutledge T, Hogan BE. A quantitative review of prospective evidence linking psychological factors with hypertension development. Psychosom Med 2002;64(5):758-66.

8. Markovitz JH, Matthews KA, Kannel WB, Cobb JL, D’Agostino RB. Psychological predictors of hypertension in the Framingham Study. Is there tension in hypertension? JAMA 1993;270(20):2439-43.

9. DASS-21. Available from: http://www.scireproject.com/depressionanxiety-stress-scale-21-dass21. [Last accessed on $2013 \mathrm{Feb}$ ].

10. Hart JT. Hypertension, Liability of General Practitioner Series. New York: Churchill Livingstone; 1980.

11. Park K. Hypertension. Parks Textbook of Preventive \& Social Medicine $23^{\text {rd }}$ ed. Jabalpur: Banarsidas Bhanot Publishers; 2015. p. 372-7.

12. Egan BM, Lackland DT, Cutler NE. Awareness, knowledge, and attitudes of older Americans about high blood pressure: Implications for health care policy, education, and research. Arch Intern Med 2003;163(6):681-7.

13. Joffres MR, Ghadirian P, Fodor JG, Petrasovits A, Chockalingam A, Hamet P. Awareness, treatment, and control of hypertension in Canada. Am J Hypertens 1997;10:1097-102.

14. Elkhalifa AM, Kinsara AJ, Almadani DA. Prevalence of hypertension in a population of healthy individuals. Med Princ Pract 2011;20(2):152-5.

15. Grimsrud A, Stein DJ, Seedat S, Williams D, Myer L. The association between hypertension and depression and anxiety disorders: Results from a nationally-representative sample of South African adults. PLoS One 2009;4(5):e5552.

16. Han J, Yin XM, Xu F, Hong X, Liang YQ, Wang ZY. A case-control study on depression and anxiety in hypertensive patients. Zhonghua Liu Xing Bing Xue Za Zhi 2008;29(2):125-7.

17. Roest AM, Martens EJ, de Jonge P, Denollet J. Anxiety and risk of incident coronary heart disease: A meta-analysis. J Am Coll Cardiol 2010;56(1):38-46.

18. Rostrup M, Kjeldsen SE, Eide IK. Awareness of hypertension increases blood pressure and sympathetic responses to cold pressor test. Am J Hypertens 1990;3:912-7.

19. Chris Woolston MS. Depression and High Blood Pressure. Available from: https://www.consumer.healthday.com/encyclopedia/ depression-12/depression-news-176/depression-and-high-bloodpressure 644943.html. [Last updated on 2016 Jan 20].

20. Spruill TM, Pickering TG, Schwartz JE, Mostofsky E, Ogedegbe G, Clemow L, et al. The impact of perceived hypertension status on anxiety and the white coat effect. Ann Behav Med 2007;34(1):1-9.

21. Bane C, Hughes CM, McElnay JC. The impact of depressive symptoms and psychosocial factors on medication adherence in cardiovascular disease. Patient Educ Couns 2006;60(2):187-93.

22. Licht CM, de Geus EJ, Seldenrijk A, van Hout HP, Zitman FG, van Dyck R, et al. Depression is associated with decreased blood pressure, but antidepressant use increases the risk for hypertension. Hypertension 2009;53(4):631-8.

23. Nakanishi N, Yoshida H, Nagano K, Kawashimo H, Nakamura K, Tatara K. Long working hours and risk for hypertension in Japanese male white collar workers. J Epidemiol Community Health 2001;55(5):316-22. 